\title{
Hamilton-Jacobi 偏微分方程式の粘性解を 用いた三輪移動体の制御
}

\author{
今 福 啓* 山下裕* 西谷紘 一*

\section{Control of a Wheeled Vehicle Using the Viscosity Solution of the Hamilton-Jacobi Partial Differential Equation}

Kei Imafuku*, Yuh Yamashita* and Hirokazu Nishitani*

\begin{abstract}
To construct an optimal regulator for nonlinear systems, we need to solve a Hamilton-Jacobi partial differential equation (HJ-PDE). However, if the system has nonholonomic constraints, the HJ-PDE has a nonsmooth solution because of the nonsmoothness of the optimal cost function. In such a case, the viscosity solution, a nonsmooth weak solution of the HJ-PDE, is obtained.

In this paper, we deal with a wheeled vehicle, which is a nonholonomic system, and propose a numerical method to achieve a viscosity solution of the HJ-PDE using the dynamic programming principle (DPP). The DPP can be applied to acquire a nonsmooth solution of the HJ-PDE. We also construct an optimal control law using derivatives of the viscosity solution of the HJ-PDE. The effectiveness of the proposed method is shown through simulations.
\end{abstract}

Key Words: Hamilton-Jacobi Partial Differential Equation, Viscosity Solution, Nonlinear Control Theory

\section{1.はじめに}

ドリフト項をもたないノンホロノミックシステムは，滑らか な時不変の状態フィードバックでは漸近安定とすることができ ないことが知られており，それを満たさないように漸近安定化 制御則を構成する方法が多く提案されている $[6]$ 亿8]. それら の制御則の多くが, 座標変換と入力変換によってチェインド . フォームと呼ばれる正準系に変換したものに対して構成されて いる.

一方，ノンホロノミックシステムは非線形系であることから， 非線形最適レギュレータを構成することで系を漸近安定とする 方法も考えられる。しかし，このような制御則を構成するため には, Hamilton-Jacobi 偏微分方程式の解の偏微分值が必要と なり, いかにしてその解を求めるのかが問題となる。さらに, ノンホロノミック拘束をもつシステムでは, 評価関数の最小值 が滑らかではないことから Hamilton-Jacobi 偏微分方程式が 粘性解 [1] [2] と呼ばれる微分不可能な点を含むものしかもたず, 一般的に用いられるような偏微分方程式の解法では解を求める ことができない.

そこで, 本論文ではノンホロノミックシステムの一つである 三輪移動体をとりあげ, 非線形最適レギュレー夕を構成する方 法について述べる. 非線形最適レギュレータを構成する際には, 先に述べたように Hamilton-Jacobi 偏微分方程式の粘性解が

原稿受付 1998 年 6 月 25 日

*奈良先端科学技術大学院大学

${ }^{*}$ Nara Institute of Science and Technology
必要となるが，これが評価関数の最小值に一致していることを 利用して, 動的計画法を用いて解を求める. 動的計画法を用い ることで，この解が粘性解となる場合でも求めることができる. そして, 求めた粘性解をスプライン関数によって近似し, それ を微分することで粘性解の偏微分值の近似值を求め, 制御則を 構成する方法についても示す。また，シミュレーションを行い， 提案さ机た手法の有効性について検討する。

\section{2. 三 輪 移 動 体}

Fig. 1 において示される三輪移動体のモデルは, 次式のよう になる。

$$
\begin{aligned}
& \dot{x}=\dot{r} \cos \theta \\
& \dot{y}=\dot{r} \sin \theta \\
& \dot{\theta}=\frac{1}{L} \dot{r} \tan \alpha
\end{aligned}
$$

$(x, y)$ は三輪移動体の位置， $\theta$ は姿勢角， $L$ は長さ， $\dot{r}$ は速度， そして $\alpha$ は操舵角である。また, 状態拉よび入力をそれぞれ

$$
\phi=\left[\begin{array}{l}
x \\
y \\
\theta
\end{array}\right], u=\left[\begin{array}{l}
u_{1} \\
u_{2}
\end{array}\right]=\left[\begin{array}{c}
\dot{r} \\
\dot{r} \tan \alpha
\end{array}\right]
$$

とする.このようなモデルは, 座標変換 $\xi_{1}=x, \xi_{2}=\tan \theta$, $\xi_{3}=y$ と入力変換 $v_{1}=\cos \theta u_{1}, v_{2}=u_{2} / \cos ^{2} \theta$ により

$$
\dot{\xi_{1}}=v_{1}
$$






Fig. 1 Wheeled vehicle

$$
\begin{aligned}
& \dot{\xi_{2}}=v_{2} \\
& \dot{\xi_{3}}=\xi_{2} v_{1}
\end{aligned}
$$

のようなチェインド・フォームと呼ばれる形式に変換できるとい うことがよく知られているが，この形式で表されるのは元のシ ステムである式 (1) のうち $\theta \in(-\pi / 2, \pi / 2)$ の範囲に限られ ている.すなわち, 通常よく用いられているチェインド・フォー ムに対して構成される制御則 [6]～[8]は，切りかえしなしでは 漸近安定とすることができない $\theta \in\{[-\pi,-\pi / 2],[\pi / 2, \pi]\}$ の 範井を初期值とする場合を除いたものとなっている.

本論文では式（1）に対して非線形最適レギュレータを構成 する。これよって，チェインド・フォームで除いている切り かえしが必要な $\theta \in\{[-\pi,-\pi / 2],[\pi / 2, \pi]\}$ の範囲に初期值が ある場合でも，漸近安定となる制御則が構成できる.

\section{3. 偏微分方程式の粘性解}

開集合 $\Omega$ において定義された次の偏微分方程式

$$
H\left(x, V(x), \frac{\partial V}{\partial x}(x)\right)=0
$$

を考える、ただし， $V$ は $C^{0}$ 級以上とする。また， $H$ は

$$
H(x, r, p) \leq H(x, s, p) \quad(r \leq s)
$$

を満たすものとする。このとき， $V(x)$ が式 $(3)$ の粘性劣解で あるとは, $\varphi \in C(\Omega)$ であり, $V-\varphi$ が $\bar{x}$ において極大值をと るならば

$$
H\left(\bar{x}, V(\bar{x}), \frac{\partial \varphi}{\partial x}(\bar{x})\right) \leq 0
$$

が成り立つことをいう。また， $V(x)$ が粘性優解であるとは， $\varphi \in C(\Omega)$ であり, $V-\varphi$ が $\bar{x}$ に扔いて極小値をとるならば

$$
H\left(\bar{x}, V(\bar{x}), \frac{\partial \varphi}{\partial x}(\bar{x})\right) \geq 0
$$

が成り立つことをいう。そして, 粘性少解でもあり粘性優解で もあるものが粘性解である [1] [2]. このように, 粘性解は偏微 分方程式の解の微分可能性を必要としない弱解の概念として知 られている.

ほとんどすべての点において式 (3) を満たし, 無数の点で 折れ曲がるような解 (すなわち少解あるいは優解) は無数に存
在するが, 粘性解は唯一な大域的最適解である。これは, 解の 一意性を証明する際に用いられる比較定理が粘性解に対しても 成り立つことから証明されている [1]. そこで, 粘性解が一意に 求められることを利用して, 次節では動的計画法を用いること で, Hamilton-Jacobi 偏微分方程式の粘性解を求める方法につ いて述べる。

\section{4. 動的計画法による Hamilton-Jacobi 偏微分方程式 の解法}

式（1）に対し，次の評価関数を最小にするという問題を考 える.

$$
J(\phi, u)=\int_{0}^{\infty}\left(x^{2}+y^{2}+\theta^{2}+u_{1}^{2}+u_{2}^{2}\right) d t
$$

このとき，上式を最小にするような最適制御則 $u_{1}, u_{2}$ は, Hamilton-Jacobi 偏微分方程式

$$
\begin{gathered}
H\left(\phi, \frac{\partial V}{\partial \phi}\right) \\
=-\frac{1}{4}\left\{\left(\frac{\partial V}{\partial x}\right)^{2} \cos ^{2} \theta+2 \frac{\partial V}{\partial x} \frac{\partial V}{\partial y} \cos \theta \sin \theta\right. \\
\left.+\left(\frac{\partial V}{\partial y}\right)^{2} \sin ^{2} \theta+\frac{1}{L^{2}}\left(\frac{\partial V}{\partial \theta}\right)^{2}\right\} \\
+x^{2}+y^{2}+\theta^{2}=0 \\
V(\phi) \geq 0, V(0)=0
\end{gathered}
$$

の粘性解 $V$ を用いて

$$
\begin{gathered}
u_{1}=-\frac{1}{2}\left(\frac{\partial V}{\partial x} \cos \theta+\frac{\partial V}{\partial y} \sin \theta\right) \\
u_{2}=-\frac{1}{2} \cdot \frac{1}{L} \frac{\partial V}{\partial \theta}
\end{gathered}
$$

と求めることができる。一般的に Hamilton-Jacobi 偏微分方 程式の粘性解を求めるのは難しいが，本論文では $V$ が

$$
V(\phi)=\min _{u} J(\phi, u)
$$

のように評価関数の最小值となることを利用して, 動的計画法 を用いることによって，式（8）の Hamilton-Jacobi 偏微分方 程式の粘性解を求める方法を考える.

まず最初に，式 $(7)(12)$ を時間間隔 $\Delta T$ で離散化し, 動的 計画法を用いると

$$
\begin{aligned}
& J_{d}(\phi, u)=\sum_{k=0}^{\infty}\left\{\phi^{2}(k+1)+u^{2}(k)\right\} \Delta T \\
& V_{d}(\phi(k))=\min _{u(k)}\left\{V_{d}(\phi(k+1))\right. \\
& \left.+\left(\phi^{2}(k+1)+u^{2}(k)\right) \Delta T\right\}
\end{aligned}
$$

となる. 式 (14) が, 動的計画法の基本式である. 状態 $\phi=$ $[x, y, \theta]^{T}$ に関しても同様に時間間隔 $\Delta T$ で離散化することに 
よって, $\dot{\theta} \neq 0$ のとき

$$
\begin{aligned}
x(k+1)= & x(k)+\frac{u_{1}(k)}{u_{2}(k)} L\left\{\sin \left(\frac{1}{L} u_{2}(k) \Delta T+\theta(k)\right)\right. \\
& -\sin \theta(k)\} \\
y(k+1)= & y(k)-\frac{u_{1}(k)}{u_{2}(k)} L\left\{\cos \left(\frac{1}{L} u_{2}(k) \Delta T+\theta(k)\right)\right. \\
& -\cos \theta(k)\} \\
\theta(k+1)= & \theta(k)+\frac{1}{L} u_{2}(k) \Delta T
\end{aligned}
$$

が得られる. $\dot{\theta}=0$ のときには $u_{2}=0$ となることを考慮して 離散化すると

$$
\begin{aligned}
& x(k+1)=x(k)+u_{1}(k) \cos \theta(k) \Delta T \\
& y(k+1)=y(k)+u_{1}(k) \sin \theta(k) \Delta T \\
& \theta(k+1)=\theta(k)
\end{aligned}
$$

となる.

ここで, 求める粘性解 $V_{d}$ の範囲と, その範甩内の格子上の 点の座標を決定する， $V_{d}$ を求める範讲を

$$
\begin{aligned}
& x \in\left[x_{\min }, x_{\max }\right] \\
& y \in\left[y_{\min }, y_{\max }\right] \\
& \theta \in[-\pi, \pi]
\end{aligned}
$$

とし，その範囲内をそれぞれ $\eta_{x}, \eta_{y}, \eta_{\theta}$ 分割する。ただし，上 式で定義される解を求める範讲は, 原点と原点に可到達な領域 が含まれるように決定する必要がある，以上の手順で形成され た格子上の座標を

$$
\begin{aligned}
x_{l} & =x_{\min }+\frac{x_{\max }-x_{\min }}{\eta_{x}} l, l=0, \cdots, \eta_{x} \\
y_{m} & =y_{\min }+\frac{y_{\max }-y_{\min }}{\eta_{y}} m, m=0, \cdots, \eta_{y} \\
\theta_{n} & =-\pi+\frac{2 \pi}{\eta_{\theta}} n, n=0, \cdots, \eta_{\theta}
\end{aligned}
$$

とする.

最後に，式（13）を最小とするような入力 $u$ を探索し， $V_{d}$ を求める方法について考える， $V_{d}$ を求める範囲が決定された ことにより，入力の範囲も制限される。 そこで，制限された範 囲内で入力を変化させ, 式（14）の右辺を満たすような入力 $u$ を見つける. $\dot{\theta} \neq 0$ のとき，式（17）より $\theta$ は $u_{2} に$ にの比例 していることから，まずは $u_{2}$ の上限，下限をそれぞれ

$$
\begin{aligned}
& u_{2 \max }=\frac{L(\pi-\theta(k))}{\Delta T} \\
& u_{2 \min }=\frac{L(-\pi-\theta(k))}{\Delta T}
\end{aligned}
$$

のように決定し $\left(u_{2 \min }>u_{2 \max }\right.$ の場合には式 $(25)$ の右辺と 式 (24)の右辺を入れかえる)，その範囲を $\lambda_{2}$ 分割した一点

$$
u_{2 j}=u_{2 \min }+\frac{u_{2 \max }-u_{2 \min }}{\lambda_{2}} j, j=0, \cdots, \lambda_{2}
$$

に $u_{2}$ を固定して, 今度は $u_{1}$ を変化させる。 $u_{2}$ が 固定されたことにより，式（15）(16）と先に決定した $\left[x_{\min }, x_{\max }\right],\left[y_{\min }, y_{\max }\right]$ から, $u_{1}$ の上限 $u_{1 \max }$ と下限 $u_{1 \text { min }}$ が決定できる. $\sin \theta(k+1)-\sin \theta(k) \neq 0$ のとき, 式（15）を $u_{1}(k)$ について解いた

$$
u_{1}(k)=\frac{u_{2}(k)(x(k+1)-x(k)}{L\left\{\sin \left(u_{2}(k) \Delta T / L+\theta(k)\right)-\sin \theta(k)\right\}}
$$

の $x(k+1) に x_{\min }, x_{\max }$ を代入したものをそれぞれ $u_{1 l i m 1}, u_{1 l i m 2}, \cos \theta(k+1)-\cos \theta(k) \neq 0$ のとき, 式（16） を $u_{1}(k)$ について解いた

$$
u_{1}(k)=-\frac{u_{2}(k)(y(k+1)-y(k))}{L\left\{\cos \left(u_{2}(k) \Delta T / L+\theta(k)\right)-\cos \theta(k)\right\}}
$$

の $y(k+1) に y_{\min }, y_{\max }$ を代入したものをそれぞれ $u_{1 \mathrm{lim} 3}, u_{1 \mathrm{lim} 4}$ とする。ここで, $u_{1 \mathrm{lim} 1}, u_{1 \mathrm{lim} 2}, u_{1 \mathrm{lim} 3}, u_{1 \mathrm{lim} 4}$ はそれぞれ三輪移動体が現在位置から $x_{\min }, x_{\max }, y_{\min }, y_{\max }$ に 到達するのに必要な入力である. $u_{1 l i m 1}, u_{1 l i m 2}, u_{1 l i m 3}, u_{1 l i m 4}$ のうち，最も大きいものと最も小さいものは， $V_{d}$ を得たい範 井の外に到達する入力となっていることから，それ以外の二っ のうち小さいものを $u_{1 \min }$, 大きいものを $u_{1 \max }$ としてその 範囲を $\lambda_{1}$ 分割した一点

$$
u_{12}=u_{1 \min }+\frac{u_{1 \max }-u_{1 \min }}{\lambda_{1}} i, i=0, \cdots, \lambda_{1}
$$

に $u_{1}$ を固定し, 式 (14) の右辺

$$
V_{d}(\phi(k+1))+\left(\phi^{2}(k+1)+u^{2}(k)\right) \Delta T
$$

を計算する。これを $i=0, \cdots, \lambda_{1}, j=0, \cdots, \lambda_{2}$ に関し て繰り返し行い, 式 (30) が最小となるような入力 $u$ を 見つける。なお， $\sin \theta(k+1)-\sin \theta(k)=0$ のときには $u_{1 \mathrm{lim} 3}, u_{1 \mathrm{lim} 4}$ のうち小さいものを $u_{1 \mathrm{~min}}$, 大きいものを $u_{1 \max }$ とし, $\cos \theta(k+1)-\cos \theta(k)=0$ のときには $u_{1 l i m 1}, u_{1 l i m 2}$ のうち小さいものを $u_{1 \min }$, 大きいものを $u_{1 \max }$ として, 同 様の手順を行う。 $\dot{\theta}=0$ のときには, 式（27）の代わりに，式 (18)を $u_{1}(k)$ について解いた

$$
u_{1}(k)=\frac{x(k+1)-x(k)}{\cos \theta(k)}
$$



$$
u_{1}(k)=\frac{y(k+1)-y(k)}{\sin \theta(k)}
$$

を用いて同様の手順を行う。

式（30）を最小とするような $u_{1}$ が求められたならば，今度は

$$
\begin{aligned}
& u_{1 \min }=-\frac{u_{1 \max }-u_{1 \text { min }}}{\lambda_{1}} \\
& u_{1 \max }=\frac{u_{1 \max }-u_{1 \min }}{\lambda_{1}}
\end{aligned}
$$

と置きかえて，先ほどと同様に式（33）(34）で決定された新 たな $\left[u_{1 \mathrm{~min}}, u_{1 \mathrm{max}}\right]$ の範囲内で, 式 $(30)$ を最小とするよう な $u_{1}$ を求める.この手順によって, 式 (30) をより小さくす 
るような $u_{1}$ を探索することができる。そして，最小のものを $\left(x_{l}, y_{m}, \theta_{n}\right)$ における $V_{d}(\phi(k))$ として記憶する。

以上の手順をすべての $\left(x_{l}, y_{m}, \theta_{n}\right)$ に関して繰り返し行い, $V_{d}(\phi(k+1))$ と $V_{d}(\phi(k))$ との差が十分小さくなったならば, $V_{d}(\phi(k))$ を求める粘性解として終了する。この $V_{d}(\phi(k+1))$ と $V_{d}(\phi(k))$ との差は, 真の解と数值解との間の誤差をどの程 度までゆるすのかということに依存していることから，必要な 精度に応じて差の絶対值を決定すればよい。

ここで提案する手法をまとめると，次のようになる。

Step 1 Hamilton-Jacobi 偏微分方程式の粘性解を得たい $(x, y, \theta)$ の範囲を, 原点と原点に可到達な領域が含まれる ように決定する。 そしてこの範囲をそれぞれ $\eta_{x}, \eta_{y}, \eta_{\theta}$ 分 割し，格子を構成する。

Step 2 格子上の一点から, 解を得たい範囲の境界までの入力 $u_{1}$ の上限，下限を， $\dot{\theta} \neq 0$ のときには式 $(27)(28)$ を, $\dot{\theta}=0$ のときには式 (31)(32) を用いて， $u_{2}$ の上限，下 限をそれぞれ式 $(24)(25)(\dot{\theta}=0$ のときには 0 となる $) の$ ように求め, それぞれ $\lambda_{1}, \lambda_{2}$ 分割する。

Step 3 Step 2 で決定された入力を， $\dot{\theta} \neq 0$ のときには式 (15)


して次のステップの状態を求め, それを式 $(30)$ に代入し て, その最小値と最小值を与える $u_{1}, u_{2}$ を求める.

Step 4 Step 3 で得られた $u_{1}$ より，今度は $u_{1 \min } u_{1 \max }$ をそ れぞれ式（33)(34) のようにおきかえて，Step 3 をもう 一度行う。ここで得られた式 $(30)$ の最小值を, その格子 点における $V_{d}$ として記憶する。

Step $5 V_{d}(\phi(k+1))$ と $V_{d}(\phi(k))$ との間の差が十分に小さく なったならば終了する。そうでなければ Step 2 にもどる.

Hamilton-Jacobi 偏微分方程式の粘性解を求める別の方法と して，有限差分近似を用いる方法が知られている [9] [10]. 有限 差分近似では粘性解の偏微分值を一次近似で近似していること から，格子間隔を極めて小さくとらなければ解の精度が悪くな るということが考えられる。しかし本手法ではそのような近似 をしていないことから，格子間隔をそれほど小さくとることな く良い精度の粘性解を求めることができると考えられる，実際， 後に示すシミュレーション結果より，本論文に扔ける手法のほ うが有限差分近似法よりも良い精度となっていることが分かる。

\section{Hamilton-Jacobi 偏微分方程式の粘性解を用いた 制御則の計算法}

式（10)(11）で表される制御則を計算するためには，前章で 求めた Hamilton-Jacobi 偏微分方程式の粘性解を状態 $\phi$ で偏 微分した值が必要となる。そこで， $V(\phi)$ をスプライン関数を 用いて近似し，それを微分して $\partial V / \partial \phi$ の近似值を求める方法 について述べる。

三輪移動体が， $\phi_{r}=\left(x_{r}, y_{r}, \theta_{r}\right)$ にあるとする。このとき， $V\left(x, y_{r}, \theta_{r}\right)$ が得られれば, それを $x$ に関して微分して $x=x_{r}$ を代入することで $\partial V / \partial x\left(x_{r}, y_{r}, \theta_{r}\right)$ を求めることができる. よって，まずは $(x, y, \theta)=\left(x_{l}, y_{m}, \theta_{r}\right)\left(l=0, \cdots, \eta_{x}, m=\right.$ $\left.0, \cdots, \eta_{y}\right)$ における $V$ の近似值 $V\left(x_{l}, y_{m}, \theta_{r}\right)$ を求めるために,
$V\left(x_{l}, y_{m}, \theta\right)$ を

$$
\begin{aligned}
V\left(x_{l}, y_{m}, \theta\right) \approx & a_{0}^{l, m}+a_{1}^{l, m} \theta+c_{0}^{l, m}\left(\theta-\theta_{0}\right)_{+}^{3}+c_{1}^{l, m}\left(\theta-\theta_{1}\right)_{+}^{3} \\
& +\cdots+c_{\eta_{\theta}}^{l, m}\left(\theta-\theta_{\eta_{\theta}}\right)_{+}^{3}
\end{aligned}
$$

で近似する。侙に扔いて, $\left(\theta-\theta_{i}\right)_{+}^{3}\left(i=0, \cdots, \eta_{\theta}\right)$ は

$$
\left(\theta-\theta_{i}\right)_{+}^{3}=\left\{\begin{array}{cc}
\left(\theta-\theta_{i}\right)^{3} & \left(\left(\theta-\theta_{i}\right)>0\right) \\
0 & \left(\left(\theta-\theta_{i}\right) \leq 0\right)
\end{array}\right.
$$

を意味する。また $a_{0}^{l, m}, a_{1}^{l, m}, c_{0}^{l, m}, \cdots, c_{\eta_{\theta}}^{l, m}$ は定数であり

$$
\begin{gathered}
a_{0}^{l, m}+a_{1}^{l, m}+c_{0}^{l, m}+c_{1}^{l, m}+\cdots+c_{\eta_{\theta}}^{l, m}=0 \\
c_{0}^{l, m} \theta_{0}+c_{1}^{l, m} \theta_{1}+\cdots+c_{\eta_{\theta}}^{l, m} \theta_{\eta_{\theta}}=0
\end{gathered}
$$

を満たす. $V\left(x_{l}, y_{m}, \theta_{0}\right), \cdots, V\left(x_{l}, y_{m}, \theta_{\eta_{\theta}}\right)$ を式 (35) に代入 して $a_{0}^{l, m}, a_{1}^{l, m}, c_{0}^{l, m}, \cdots, c_{\eta_{\theta}}^{l, m}$ を決定し， $\theta=\theta_{r}$ を代入するこ とにより, $V\left(x_{l}, y_{m}, \theta_{r}\right)$ が得られる.

次に, 式 (35) で与えられる $V\left(x_{l}, y_{m}, \theta_{r}\right)$ を用いて $V\left(x_{l}, y_{r}, \theta_{r}\right)$ を求める. 4 節で求めた粘性解 $V$ が，任意の $\theta$ に打いて $x$ 軸, $y$ 軸上で微分不可能となっていることが 6 節 のシミュレーション結果より見てとることができることから， 以下のように $y_{r}$ が正の場合と負の場合をわけてスプライン関 数を構成し， $x$ 軸近傍における $V$ の偏微分値が不連続となる ようにする。

$$
V\left(x_{l}, y, \theta_{r}\right) \approx\left\{\begin{array}{cc}
a_{0}^{l}+a_{1}^{l} y+c_{0}^{l}\left(y-y_{0}\right)_{+}^{3}+c_{1}^{l}\left(y-y_{1}\right)_{+}^{3} \\
\quad+\cdots+c_{\eta_{y} / 2}\left(y-y_{\eta_{y} / 2}\right)_{+}^{3} & \left(y_{r}<0\right) \\
a_{0}^{l}+a_{1}^{l} y+c_{0}^{l}\left(y-y_{\eta_{y} / 2}\right)_{+}^{3} & \\
& +c_{1}^{l}\left(y-y_{\eta_{y} / 2+1}\right)_{+}^{3} \\
& +\cdots+c_{\eta_{y} / 2}^{l}\left(y-y_{\eta_{y}}\right)_{+}^{3} \quad\left(y_{r} \geq 0\right)
\end{array}\right.
$$

もし $y_{r}<0$ ならば $V\left(x_{l}, y_{0}, \theta_{r}\right), \cdots, V\left(x_{l}, y_{\eta_{y} / 2}, \theta_{r}\right)$ を, $y_{r} \geq 0$ ならば $V\left(x_{l}, y_{\eta_{y} / 2}, \theta_{r}\right), \cdots, V\left(x_{l}, y_{\eta_{y}}, \theta_{r}\right)$ を式 (36) に代入して $a_{0}^{l}, a_{1}^{l}, c_{0}^{l}, \cdots, c_{\eta_{y} / 2}^{l}$ を決定し,$y=y_{r}$ を代入する ことで, $V\left(x_{l}, y_{r}, \theta_{r}\right)$ が求めら机る.

最後に，上の手順で得られた $V\left(x_{l}, y_{r}, \theta_{r}\right)$ を用いて $V\left(x, y_{r}, \theta_{r}\right)$ を求める. 先ほどと同様に $y$ 軸近傍で $V$ の偏 微分值が不連続となるようにするために， $x_{r}$ が正の場合と負 の場合をわけて，次のようにスプライン関数を構成する.



$x_{r}<0$ のときには $V\left(x_{0}, y_{r}, \theta_{r}\right), \cdots, V\left(x_{\eta_{x} / 2}, y_{r}, \theta_{r}\right)$ を, $x_{r} \geq 0$ のときには $V\left(x_{\eta_{x} / 2}, y_{r}, \theta_{r}\right), \cdots, V\left(x_{\eta_{x}}, y_{r}, \theta_{r}\right)$ を式 (37) に代入して $a_{0}, a_{1}, c_{0}, \cdots, c_{\eta_{x} / 2}$ を決定する。 そして, 求めた $V\left(x, y_{r}, \theta_{r}\right)$ を $x$ に関して微分して $x=x_{r}$ を代入 することによって, $\partial V / \partial x\left(x_{r}, y_{r}, \theta_{r}\right)$ の近似值が得られる。 $\partial V / \partial y\left(x_{r}, y_{r}, \theta_{r}\right), \partial V / \partial \theta\left(x_{r}, y_{r}, \theta_{r}\right)$ に関しても, 以上の手順 と同様にして求めることができる. 
三輪移動体が原点のまわりの一格子内に到達したときには， 後に示すシミュレーション結果のように微分不可能となる点が 複雑になっており, 微分不可能点を考慮したスプライン関数に よる近似では偏微分項がうまく表現できないと考えられる。そ こで, $\partial V / \partial x, \partial V / \partial y$ の計算法を, $u_{1} \neq 0$ のとき

$$
\begin{aligned}
& \frac{\partial V}{\partial x}\left(x_{r}, y_{r}, \theta_{r}\right) \approx \frac{V\left(x_{r}+\Delta x, y_{r}, \theta_{r}\right)-V\left(x_{r}-\Delta x, y_{r}, \theta_{r}\right)}{2 \cdot \Delta x} \\
& \frac{\partial V}{\partial y}\left(x_{r}, y_{r}, \theta_{r}\right) \approx \frac{V\left(x_{r}, y_{r}+\Delta y, \theta_{r}\right)-V\left(x_{r}, y_{r}-\Delta y, \theta_{r}\right)}{2 \cdot \Delta y}
\end{aligned}
$$

$u_{1}=0$ のとき

$$
\begin{aligned}
& \frac{\partial V}{\partial x}\left(x_{r}, y_{r}, \theta_{r}\right) \approx \begin{cases}\frac{V\left(x_{r}+\Delta x, y_{r}, \theta_{r}\right)-V\left(x_{r}, y_{r}, \theta_{r}\right)}{\Delta x} & \left(x_{r} \geq 0\right) \\
\frac{V\left(x_{r}, y_{r}, \theta_{r}\right)-V\left(x_{r}-\Delta x, y_{r}, \theta_{r}\right)}{\Delta x} & \left(x_{r}<0\right) \\
(40)\end{cases} \\
& \frac{\partial V}{\partial y}\left(x_{r}, y_{r}, \theta_{r}\right) \approx \begin{cases}\frac{V\left(x_{r}, y_{r}+\Delta y, \theta_{r}\right)-V\left(x_{r}, y_{r}, \theta_{r}\right)}{\Delta y} & \left(y_{r} \geq 0\right) \\
\frac{V\left(x_{r}, y_{r}, \theta_{r}\right)-V\left(x_{r}, y_{r}-\Delta y, \theta_{r}\right)}{\Delta y} & \left(y_{r}<0\right)\end{cases}
\end{aligned}
$$

とする。上式において， $\Delta x, \Delta y$ はそれぞれ

$$
\Delta x=\frac{x_{\max }-x_{\min }}{\eta_{x}}, \Delta y=\frac{y_{\max }-y_{\min }}{\eta_{y}}
$$

である。式 $(40)(41)$ は, 三輪移動体が $x$ 軸上, あるいは $y$ 軸上に位置するときに, 入力 $u_{1} \neq 0$ となるようにするため である。あとは, 求められた偏微分值の近似值を式 $(10)(11)$ に代入することによって, 点 $\left(x_{r}, y_{r}, \theta_{r}\right)$ に抄ける最適制御則 $u_{1}, u_{2}$ を計算することができる.

三輪移動体が初期点から原点近傍の一格子内に到達すると, その内部ではスプライン関数を用いても $V$ の近似に誤差が牛 じることから，格子間隔が大きい場合には一格子内に扮いて原 点への収束が期待どおりの精度とはならないことが考えられる. そこで，4 章で述べた方法を原点を含む単位格子内において， すなわち先の $x_{\min }, x_{\max }, y_{\min }, y_{\max }$ を

$$
\begin{aligned}
& x_{\min }=-\frac{x_{\max }-x_{\min }}{\eta_{x}}, x_{\max }=\frac{x_{\max }-x_{\min }}{\eta_{x}} \\
& y_{\min }=-\frac{y_{\max }-y_{\min }}{\eta_{y}}, \quad y_{\max }=\frac{y_{\max }-y_{\min }}{\eta_{y}}
\end{aligned}
$$

と置きかえて行い，三輪移動体がその範讲内に到達した場合に は, 先に求めた粘性解と切りかえて制御則を計算する。それに よっても望んだと抢りの原点への収束が得られない場合には, さらに同様の手順を新たな一格子内に拀いても行うことで, 収 束の精度をさらに上げることができる。

また, 微分不可能となる点が格子点上ではなく, 格子点間に 存在する場合が考えられる. 入力 $u_{1}$ の符号が变化する前後の 点にそのような微分不可能な点が存在するものと考えられるこ とから， $u_{1}$ の符号が変化する前の点だけを用いて $V$ をスプラ イン関数で近似したものと, $u_{1}$ の符号が変化した後の点だけ を用いて $V$ をスプライン関数で近似したものの交点を求める ことで，格子点間における微分不可能な点を正確に求めること ができる。これによってもさらに収束の精度が上がるものと期 待できる。

\section{6. シミュレーション結果}

4, 5 章で述べた方法を用いてシミュレーションを行った。 Table 1 に, シミュレーションに用いたパラメータを示 す。また，三輪移動体が一格子の大きさよりもやや大きい $x \in[-0.3[\mathrm{~m}], 0.3[\mathrm{~m}]]$ かつ $y \in[-0.3[\mathrm{~m}], 0.3[\mathrm{~m}]]$ に入った場 合には, Hamilton-Jacobi 偏微分方程式の粘性解を求める範囲 をこの範用とし， $\eta_{x}, \eta_{y}, \eta_{\theta}$ を 12 として求めた粘性解に切りか えて, 制御則を構成した。これは, 原点近傍の一格子内におい て Table 1 で構成される格子のみを用いるよりも，より精度の 良い軌道をえるためである。

Fig. 2 に 4 章で述べた方法により求めたHamilton-Jacobi 偏微分方程式の $\theta=0$ における解を示す. Fig. 2 より, $x$ 軸, $y$ 軸上で微分不可能となっていることが分かり, 本論文で提案 した手法で求めた Hamilton-Jacobi 偏微分方程式の解が粘性 解となっていることが分かる.

また，Fig. 3, Fig. 4 は，それぞれ三輪移動体の初期值を $(0,2,0),(2,0, \pi / 2)$ とした場合の軌道である。実線が原点近傍 の一格子内での粘性解の切りかえを行わなかった場合，点線が 切りかえを行った場合である。いずれの場合も，粘性解を用い て制御則を構成したことにより軌道に切りかえしが生じている。 そして Fig. 3 ではその軌道に違いは生じないが, Fig. 4 では Hamilton-Jacobi 偏微分方程式の粘性解の切りかえを行ったこ とによって，輪移動体が $x=0.3[\mathrm{~m}]$ に到達したあたりから さらに原点に収束している。

初期值を $(0,2,0)$ としたときの，本論文における手法により 粘性解を求めた場合と，有限差分近似法により粘性解を求めた 場合のシミュレーション結果は, Fig. 5 となる. 実線が本論文

Table 1 Simulation parameters

\begin{tabular}{|c|r|}
\hline parameter & value \\
\hline$L[\mathrm{~m}]$ & 0.5 \\
\hline$x_{\min }[\mathrm{m}]$ & -3.0 \\
\hline$x_{\max }[\mathrm{m}]$ & 3.0 \\
\hline$y_{\min }[\mathrm{m}]$ & -3.0 \\
\hline$y_{\max }[\mathrm{m}]$ & 3.0 \\
\hline$\eta_{x}$ & 24 \\
\hline$\eta_{y}$ & 24 \\
\hline$\eta_{\theta}$ & 24 \\
\hline$\Delta T[\mathrm{sec}]$ & 0.1 \\
\hline
\end{tabular}



Fig. 2 Viscosity solution of the Hamilton-Jacobi partial differential equation at $\theta=0$ 


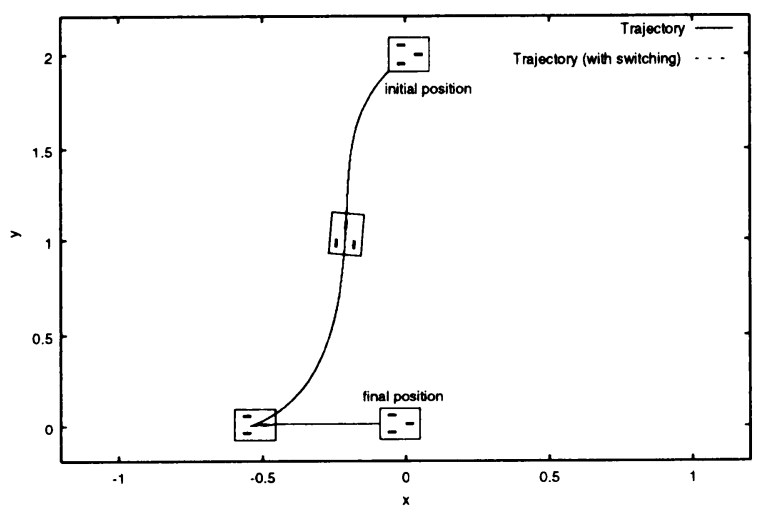

Fig. 3 Optimal trajectory from $(0,2,0)$



Fig. 4 Optimal trajectory from $(2,0, \pi / 2)$



Fig. 5 Optimal trajectory from $(0,2,0)$ (compared with finite difference method)

に扔いて提案する手法を用いて求めた粘性解を用いた場合の軌 道，点線が有限差分近似法により求めた粘性解を用いた場合の 軌道である。有限差分近似法を用いた場合は，原点近傍におい て三輪移動体の軌道に誤差が生じていることが分かる。

初期値が $(0,0, \pi / 2)$ の場合のシミュレーション結果は, Fig. 6 のようになる。先ほどと同様に，実線が原点近傍での粘性解 の切りかえを行わなかった場合, 点線が切りかえを行った場合 であるが, $(x, y)$ の初期值が原点上でありながら, 式 $(38)$ (41) で表される $\partial V / \partial x$ および $\partial V / \partial y$ の近似により, 数回の



Fig. 6 Optimal trajectory from $(0,0, \pi / 2)$



Fig. 7 Optimal trajectory from $(1,2, \pi)$ to $(2,4, \pi / 2)$

切りかえしで原点へと収束している。

終端点 $\left(x_{f p}, y_{f p}, \theta_{f p}\right)$ が原点以外の場合には, 次のような座 標変換

$$
\begin{gathered}
{\left[\begin{array}{c}
x^{\prime} \\
y^{\prime}
\end{array}\right]=\left[\begin{array}{cc}
\cos \theta_{f p} & \sin \theta_{f p} \\
-\sin \theta_{f p} & \cos \theta_{f p}
\end{array}\right]\left[\begin{array}{c}
x-x_{f p} \\
y-y_{f p}
\end{array}\right]} \\
\theta^{\prime}=\theta-\theta_{f p}
\end{gathered}
$$

を行い, $\left(x^{\prime}, y^{\prime}, \theta^{\prime}\right)$ に対して式 $(10)(11)$ で表される制御入 力を適用することで, 点 $\left(x_{f p}, y_{f p}, \theta_{f p}\right)$ に対して漸近安定と することができる. Fig. 7 に, 初期点を $(1,2, \pi)$, 終端点を $(2,4, \pi / 2)$ とした場合のシミュレーション結果を示す.

\section{7.おわりに}

本論文では, Hamilton-Jacobi 偏微分方程式の粘性解を動的 計画法を用いて求める方法と, その解を微分不可能点を考慮し て近似することで制御則を構成する方法について述べた。また シミュレーションにより，その有効性について示した。

\section{参 考 文 献}

[1] M.G. Crandall and P.L. Lions: "Viscosity solutions of Hamilton-Jacobi equations," Amer. Math. Soc., vol.277, no.1, pp.1-42, 1983.

[2]石井位司：“非線形偏微分方程式の粘性解について”, 数学, vol.46, pp.144-157, 1994.

[3] 石井仁司：“粘性解とその応用”, 数学, vol.47, pp.97-110, 1995.

[4] 中村仁彦: “非ホロノミックロボットシステム, 講座全 5 回”, 日本口 
ボット学会誌, vol.11, no.4ー7, vol.12, no.2, 1993 1994.

[5] 三平満司：“非ホロノミック系のフィードバック制御”, 計測と制御, vol.36, no.6, pp.396-403, 1997.

[6] 三平满司，伊藤毅：“非線形制御理論を用いた車両の経路追従と移動 計画”, システム制御情報学会論文誌, vol.6, no.1, pp.37-47, 1993.

[ 7 ] 成清辰生, 杉田澄雄: “Chained Form で記述された非ホロノミック系の 指数安定化”，計測自動制御学会論文集，vol.32, no.8, pp.1310-1312, 1996.



\section{今福 啓 (Kei Imafuku)}

1972 年 8 月 23 日生. 1999 年 3 月奈良先端科学技 術大学院大学情報科学研究科博士後期課程修了. 同 年 4 月より，奈良先端科学技術大学院大学情報科 学研究科助手. 非線形制御理論, ノンホロノミック システムの制御に関心在持つ.上学博士.

(日本ロボット学会正会員)



西谷紘一 (Hirokazu Nishitani)

1945 年 7 月 29 日生. 1974 年京都大学大学院工学 研究科博士課程 (化学工学専攻) 単位取得退学. 同 年大阪大学基礎工学部助手。講師, 助教授, 教授 在経て 1993 年から奈良先端科学技術大学院大学教 授。プロセス制御，プロセスシステム工学に関す る研究を行ってきた。工学博士。システム制御情報 学会, 化学丁学会, AIChEなどの会員.
[8] A. Astolfi: "Discontinuous control of nonholonomic systems," Syst. Contr. Lett., vol.27, pp.37-45, 1996.

[9] H.J. Kushner and P. Dupuis: Numerical Methods for Stochastic Control Problems in Continuous Time. Springer-Verlag, New York, 1992.

[10] W.H. Flemming and H.M. Soner: Controlled Markov Processes and Viscosity Solutions. Springer-Verlag, New York, 1993.



\section{山下 裕 (Yuh Yamashita)}

1961 年 7 月 25 日生. 1986 年 3 月北海道大学大学 院工学研究科修士課程修了。1988 年 3 月同博士課 程退学. 问年 4 月より 北海道大学工学部助手 1996 年 4 月より奈良先端科学技術大学院大学情報科学研 究科助教授, 現在に至る. 非線形制御理論, 二ュー ラルネットワークによる制御，学習制御などの研 究に従事. 博士 ( (学) . システム制御情報学会, 電子情報通信学会, 化学丁学会などの会員. 